\title{
Differentiation of cholesterol compartments in the immature chick testis
}

\author{
E. M. Massa and A. Aoki \\ Sección de Microscopia Electrónica, Universidad Nacional de Córdoba, Argentina, and Department \\ of Anatomy, Harvard Medical School, Boston, Massachusetts 02115, U.S.A.
}

\begin{abstract}
Summary. The behaviour of testicular free and esterified cholesterol during early posthatching development and after stimulation with human chorionic gonadotrophin was studied in the immature chick using combined electron microscope and biochemical techniques. The interstitial cells represented about $65 \%$ of the testicular tissue and the lipid droplets in the cytoplasm of these cells were considerably depleted after HCG treatment. The lipid droplets isolated from 7-day-old testis contained about $95 \%$ of the total esterified cholesterol which was significantly reduced in the testis and isolated lipid droplets after HCG stimulation. The bulk of free cholesterol was associated with the microsomal fraction whose membranes and cholesterol content increased during normal maturation and after gonadotrophininduced differentiation.
\end{abstract}

\section{Introduction}

The biosynthesis and secretion of testicular androgens are under the control of gonadotrophins (see Greep, 1961, for review). In adult mice, the stimulation of androgen secretion by exogenous LH is accompanied by depletion of esterified cholesterol and the inhibition of gonadotrophin secretion increases the testicular cholesterol content (Aoki \& Massa, 1975). The enhancement of androgen production and mobilization of testicular stores of cholesterol seems to indicate a direct precursor-product relationship, but in a previous study, using a combination of biochemical techniques and electron microscopy, we found that there are independent free cholesterol and esterified cholesterol compartments in the subcellular fractions of interstitial cells of the mouse testis. The compartments appeared to have different responses to hormonal stimulation and probably have distinct functions within the cell in spite of the close relationship between them (Aoki \& Massa, 1975). The complex organization of adult mouse testis, however, made the interpretation of biochemical parameters in the interstitial cells difficult when whole tissue preparations were used. Moreover, biochemical analysis was further complicated by the paucity of interstitial tissue compared to other testicular components.

In the present study, a similar approach was used to study the testis of the immature chick, the morphological and physiological peculiarities of which provide an excellent model system for study of the differentiation of the cholesterol compartments and the changes occurring in response to stimulation by exogenous gonadotrophins.

\section{Materials and Methods}

Newly hatched single-comb white Leghorn cockerels obtained from a local hatchery were used. The birds were randomly distributed in groups of $15-20$ per cage, and kept in a temperature-controlled $\left(28-30^{\circ} \mathrm{C}\right)$, artificially illuminated $(14 \mathrm{hr}$ light: $10 \mathrm{hr}$ dark) animal room. Commercial food (Vitosan BB: Molinos, Río de la Plata, Buenos Aires) and tap water were always available by automatic systems. Chicks in the various consignments varied slightly in body weight, and the expected differ- 
ences in the testicular condition were minimized by pairing each experimental group with a control of similar characteristics.

The modifications in testicular cholesterol during differentiation were recorded in normal chicks by serial determinations between 1 and 18 days of age.

The effects of gonadotrophins on the cholesterol compartments were studied in 6-day-old chicks primed with 25 i.u. HCG (ELEA, Laboratorios Endocrinicos Argentinos, Buenos Aires) $24 \mathrm{hr}$ after hatching. These were injected s.c. at the dorsal neck region with $100 \mathrm{i}$.u. HCG, in $\mathbf{0 . 2} \mathrm{ml}$ doubledistilled water, and killed at various time intervals.

In all experiments the birds were decapitated and allowed to bleed; the gonads were removed rapidly, cleaned and weighed to the nearest $0.5 \mathrm{mg}$ on a Mettler analytical balance.

\section{Preparation of subcellular fractions, lipid extraction and cholesterol determination}

The fractionation of chick testes was performed as described by Aoki \& Massa (1975). The testes were excised, washed in buffer, blotted dry and cooled on ice as quickly as possible to minimize post-mortem changes. All subsequent procedures were conducted at $4^{\circ} \mathrm{C}$. The cell fractions for each experiment were obtained from the pooled testes of 40-50 animals.

The total lipid content of testes and cell fractions were extracted by the technique of Folch, Lees \& Sloane Stanley (1957) from 10-15 mg samples of pooled tissues. The extracts, evaporated to dryness under a stream of nitrogen at $30-40^{\circ} \mathrm{C}$, were dissolved in a small volume of benzenehexene $(1: 1 \mathrm{v} / \mathrm{v})$ and fractionated by column chromatography on silicic acid (Horning, Williams \& Horning, 1960). Free and esterified cholesterol were separated by the system of solvents recommended by Creech \& Sewell (1962), and the cholesterol content of eluted fractions was determined spectrophotometrically with the $o$-phthalaldehyde method of Zlatkis \& Zak (1969). The variability of the technique was tested by processing individually the testes of 8 normal cockerels. The percentile standard deviation of the difference between individual testes from the same animal was $3 \cdot 2$ for free cholesterol and 4.8 for cholesterol esters. The recovery of a known amount of purified free cholesterol (Koch-Light, U.K.) and cholesterol oleate (B.D.H., U.K.) added at the beginning of the extraction procedure was $98.5 \pm 2.9$ (S.E.M.) \% and $96 \pm 4.3 \%$, respectively. Values for testicular free and esterified cholesterol were not corrected for losses during recovery.

All chemicals were reagent grade and the solvents were redistilled before use.

Standard $t$ tests and analysis of variance procedures were used to determine if significant differences existed between control and treated groups.

\section{Electron micrascopy}

Whole testes were fixed by immersion in a mixture of $4 \%$ glutaraldehyde and $4 \%$ formaldehyde (Karnovsky, 1965) in 0.1 M-s-collidine buffer, pH 7.3, and $20 \mathrm{~mm}$-calcium chloride. Formaldehyde was freshly prepared by depolymerization of paraformaldehyde and glutaraldehyde was purified as described by Massa \& Aoki (1971).

The testes were fixed for $2 \mathrm{hr}$ and then cut tangentially to the surface into $1-\mathrm{mm}$ thick slices which were treated with $1.33 \%$ osmium tetroxide in $0.067 \mathrm{M}$-s-collidine buffer for $4 \mathrm{hr}$. Rapid dehydration was performed in cold graded acetones followed by 3 changes $(10 \mathrm{~min}$ each) of $100 \%$ acetone at room temperature. Embedding was carried out in an araldite-epon mixture (Mollenhauer, 1964). Thin sections were cut on a Porter-Blum MT1 ultramicrotome, stained with lead citrate (Venable \& Coggeshall, 1965) and examined in an Hitachi 11B electron microscope. Sections were also cut at 0.5-1 $\mathrm{mm}$ and stained with toluidine blue-borax for light microscopy.

\section{Results}

\section{Normal structure}

The organization of the 7-day-old chick testis was described previously (Massa, 1972) and found to be similar to that reported by Connell (1972) for newly hatched chickens. The interstitial 
tissue at this age represents $62 \cdot 8 \pm 1 \cdot 2 \%$ of the total testicular volume and consists mainly of clusters of rudimentary Leydig cells (Pl. 1, Figs 1 and 2).

\section{Effects of HCG on the interstitial cell fine structure}

The administration of 100 i.u. HCG to 6-day-old chicks $24 \mathrm{hr}$ before death produced major changes in the ultrastructure of interstitial cells (Pl. 2, Fig. 3). A marked depletion of lipid droplets and proliferation of agranular endoplasmic reticulum membranes occurred in the cytoplasm. There was a considerable shift in the population of lipid inclusions to small droplets about $0.5 \mu \mathrm{m}$ in diameter, although occasionally some large droplets persisted. The agranular endoplasmic reticulum was generally tubular in shape, irregular in diameter, and contained a finely granular material, but was in places composed of branched tubules which were widely interconnected and formed a complex network of irregular membranes, often seen in association with lipid droplets and mitochondria.

The number of free ribosomes and polyribosomes also increased significantly throughout the cytoplasm. The rough endoplasmic reticulum increased to a lesser extent and appeared as short cisternae with irregularly attached ribosomes. The mitochondria increased in size and were mainly round in profile with numerous and regularly distributed cristae. The mitochondrial matrix consisted of areas with lighter density and abundant electron-dense granular inclusions. The nuclei of HCGtreated interstitial cells were less compact than those of control animals and exhibited numerous nuclear pores and a conspicuous hypertrophic nucleolus.

\section{Changes in testicular cholesterol during differentiation and after HCG treatment}

The content of free cholesterol in the chick testis increased steadily with age in parallel with the change in testicular weight, and the cholesterol:weight ratio was therefore fixed. The content and concentration of esterified cholesterol, however, reached a peak at the end of the first week and progressively diminished until the end of the experiment (Table 1). When 25 i.u. HCG were injected $24 \mathrm{hr}$ after hatching, a considerable accumulation in testicular cholesterol occurred after the expected initial depletion and maximal concentration was seen between 6 and 8 days. This treatment enhanced the response of the interstitial cells to a second dose of HCG, as judged by the cholesterol depletion and hypertrophy of the Leydig cells; primed birds therefore were used in all subsequent experiments.

Table 1. Mean ( \pm S.E.M.) concentration of free and esterified cholesterol in the testes of chicks during the first 18 days after hatching

\begin{tabular}{ccccc}
\hline $\begin{array}{c}\text { Age } \\
\text { (days) }\end{array}$ & No. of chicks & $\begin{array}{c}\text { Wt of testes } \\
(\mathrm{mg})\end{array}$ & \multicolumn{2}{c}{ Concentration of cholesterol $(\mu \mathrm{g} / \mathrm{mg})$} \\
\cline { 4 - 4 } 2 & 30 & $6 \cdot 16 \pm 0 \cdot 41$ & Free & Esterified \\
4 & 8 & $7 \cdot 30 \pm 0 \cdot 40$ & $3 \cdot 76 \pm 0 \cdot 17$ & $12 \cdot 50 \pm 0 \cdot 37$ \\
6 & 8 & $8 \cdot 20 \pm 0 \cdot 32$ & $4 \cdot 10 \pm 0 \cdot 11$ & $12 \cdot 99 \pm 0 \cdot 29$ \\
8 & 12 & $10 \cdot 80 \pm 1 \cdot 24$ & $3 \cdot 96 \pm 0 \cdot 03$ & $13 \cdot 08 \pm 1 \cdot 35$ \\
10 & 12 & $17 \cdot 90 \pm 1 \cdot 93$ & $3 \cdot 87 \pm 0 \cdot 08$ & $8 \cdot 89 \pm 0 \cdot 79$ \\
12 & 11 & $21 \cdot 70 \pm 1 \cdot 50$ & $3 \cdot 75 \pm 0 \cdot 05$ & $7 \cdot 38 \pm 1 \cdot 21$ \\
14 & 5 & $21 \cdot 80 \pm 2 \cdot 31$ & $3 \cdot 91 \pm 0 \cdot 12$ & $6 \cdot 68 \pm 0 \cdot 67$ \\
16 & 6 & $23 \cdot 70 \pm 2 \cdot 66$ & $3 \cdot 78 \pm 0 \cdot 07$ & $5 \cdot 30 \pm 1 \cdot 08$ \\
18 & 6 & $28 \cdot 45 \pm 2 \cdot 23$ & $3 \cdot 80 \pm 0 \cdot 10$ & $4 \cdot 28 \pm 0 \cdot 71$ \\
\hline
\end{tabular}

After injection of 100 i.u. HCG to 6-day-old chicks the testicular weight was significantly increased by $12 \mathrm{hr}$ and was $50 \%$ higher $(P<0.001)$ at $24 \mathrm{hr}$ (Table 2$)$. The free cholesterol content changed parallelly with the testicular weight increase and the concentration of free cholesterol hence remained 
Table 2. Effect of 100 i.u. HCG on the concentration (mean \pm S.E.M.) of free and esterified cholesterol in the testis of the chick 6 days after hatching and after priming with 25 i.u. HCG $24 \mathrm{hr}$ after hatching

\begin{tabular}{|c|c|c|c|c|}
\hline Time (hr) & No. of chicks & Wt of testes (mg) & $\begin{array}{l}\text { Free cholesterol } \\
\qquad(\mu \mathrm{g} / \mathrm{mg})\end{array}$ & $\begin{array}{l}\text { Esterified cholesterol } \\
(\mu \mathrm{g} / \mathrm{mg})\end{array}$ \\
\hline 0 & 64 & $11 \cdot 9 \pm 0.5$ & $3.89 \pm 0.05$ & $16.0 \pm 0.7$ \\
\hline 1 & 25 & $13.7 \pm 0.9$ & $3.92 \pm 0.05$ & $17 \cdot 6 \pm 1 \cdot 1$ \\
\hline 4 & 25 & $14 \cdot 0 \pm 1 \cdot 5$ & $3.76 \pm 0.08$ & $16 \cdot 5 \pm 1 \cdot 2$ \\
\hline 8 & 16 & $12 \cdot 8 \pm 1 \cdot 3$ & $3.84 \pm 0.12$ & $14 \cdot 5 \pm 0 \cdot 8$ \\
\hline 12 & 26 & $16 \cdot 0 \pm 1.0 \dagger$ & $3.74 \pm 0.08$ & $12 \cdot 5 \pm 1 \cdot 0 \ddagger$ \\
\hline 16 & 16 & $15 \cdot 0 \pm 1 \cdot 3^{*}$ & $3.73 \pm 0.11$ & $9 \cdot 0 \pm 1 \cdot 3 \S$ \\
\hline 24 & 32 & $18 \cdot 4 \pm 1 \cdot 1 \S$ & $3.85 \pm 0.07$ & $8.8 \pm 0.5 \S$ \\
\hline
\end{tabular}

Compared with values at $0 \mathrm{hr}:{ }^{*} P<0.05 ; \uparrow P<0.02 ; \ddagger P<0.01 ; \S P<0.001$.

constant. By contrast, the content of esterified cholesterol showed a small increase $1 \mathrm{hr}$ after the injection and was significantly mobilized between 12 and $16 \mathrm{hr}$. The lowest concentration was found at $24 \mathrm{hr}$ with a $45 \%$ depletion $(P<0.001)$.

Table 3. Distribution of free and esterified cholesterol $(\mu \mathrm{g} / \mathrm{mg}$, mean \pm S.E.M.) in subcellular fractions of testis of control and HCG-treated (100 i.u. $24 \mathrm{hr}$ before death) 7-day-old chicks primed with 25 i.u. HCG $24 \mathrm{hr}$ after hatching

\begin{tabular}{|c|c|c|c|c|}
\hline \multirow[b]{2}{*}{ Cell fractions* } & \multicolumn{2}{|c|}{ Control } & \multicolumn{2}{|c|}{ HCG-treated } \\
\hline & Free cholesterol & Esterified cholesterol & Free cholesterol & Esterified cholesterol \\
\hline Lipid droplets & $0.096 \pm 0.014$ & $10 \cdot 250 \pm 1.090 \dagger$ & $0.081 \pm 0.010$ & $4.34 \pm 0.500 \dagger$ \\
\hline Soluble fraction & $0.181 \pm 0.023$ & $0.077 \pm 0.014$ & $0.163 \pm 0.035$ & $0.071 \pm 0.005$ \\
\hline Microsomes & $1 \cdot 300 \pm 0 \cdot 100$ & $0.091 \pm 0.025$ & $1 \cdot 330 \pm 0.130$ & $0.750 \pm 0.015$ \\
\hline Mitochondria & $0.137 \pm 0.020$ & $0.029 \pm 0.004$ & $0.149 \pm 0.008$ & $0.021 \pm 0.002$ \\
\hline Nuclei and debris & $0.435 \pm 0.021$ & $0.226 \pm 0.040$ & $0.375 \pm 0.043$ & $0.113 \pm 0.015$ \\
\hline
\end{tabular}

* Obtained from 130 chicks allocated to 3 experiments per group.

$\uparrow$ Significantly different, $P<0 \cdot 01$.

\section{Subcellular distribution of free and esterified cholesterol}

The concentration and distribution of free and esterified cholesterol in the various testicular cell fractions obtained from control 7-day-old chicks and chicks treated with 100 i.u. HCG 24 hr before death are shown in Table 3. The bulk of free cholesterol appears associated with the microsomal fraction and the lipid droplets contained $95 \%$ of the total content of esterified cholesterol. The injection of $100 \mathrm{i} . \mathrm{u}$. HCG produced no changes in the free cholesterol concentration, but a significant decrease $(P<0.01)$ in the esterified cholesterol content of the lipid droplets.

\section{Discussion}

The fine structure of the 7-day-old chick testis revealed the presence of numerous rudimentary but well differentiated Leydig cells, as in the prepubertal testis of the mouse (Aoki, 1968, 1970) and guinea-pig (Black \& Christensen, 1969). These primitive interstitial cells must be regarded as endocrine cells since they attain the basic organization capable of androgen biosynthesis under adequate stimulation. As Connell (1972) found with LH treatment, the administration of HCG induced important changes in the interstitial tissue and only minor modifications in the germinal cords of the immature chick testis. The two major changes, the depletion of lipid droplets and the proliferation of agranular endoplasmic reticular membranes, appeared to be closely associated with cholesterol metabolism. Cholesterol determinations showed that the lipid droplets stored almost all the choles- 

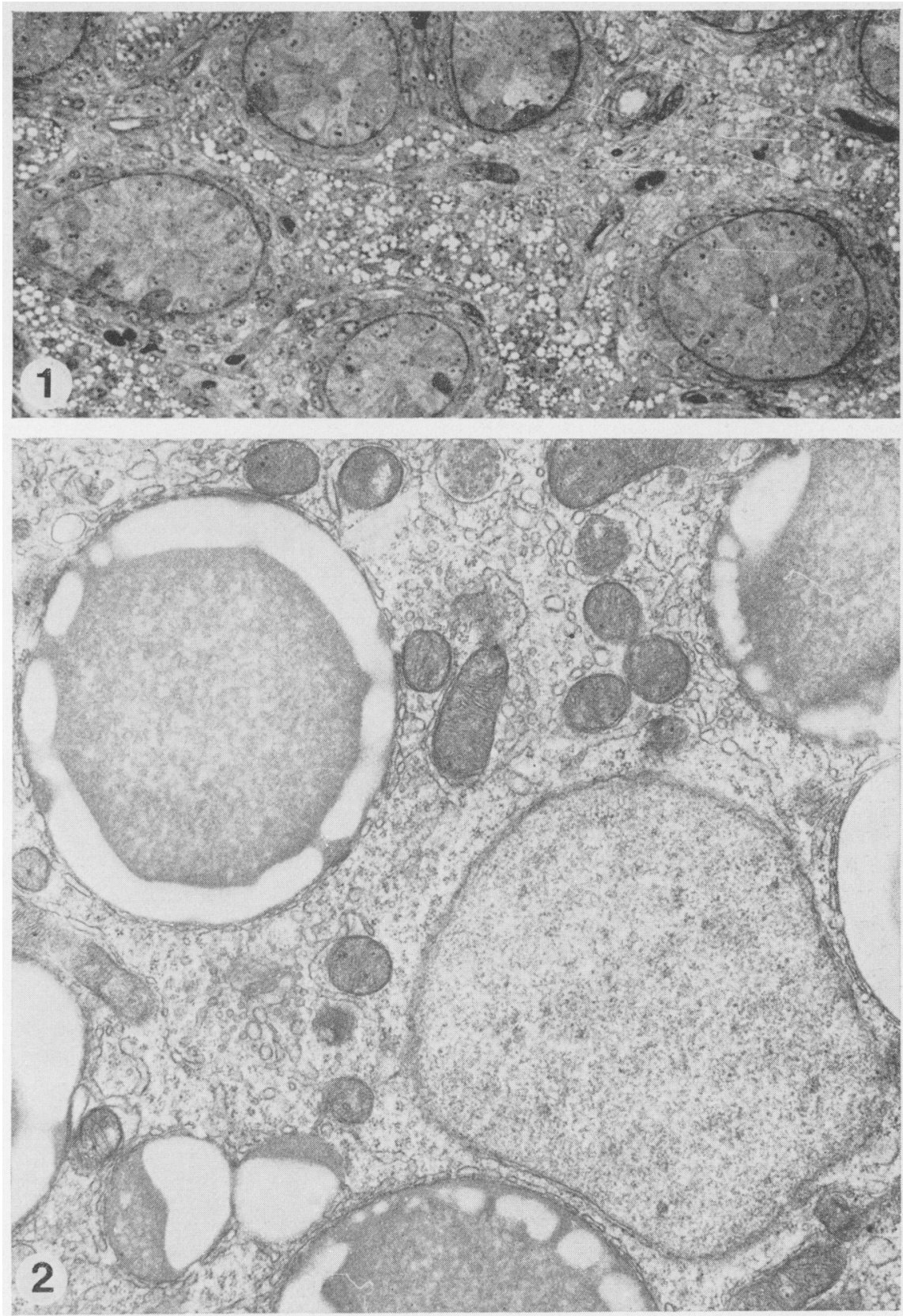

Fig. 1. Light micrograph of a section of a 7-day-old chick testis. The interstitial tissue represents a large part of the organ and consists of numerous epitheloid cells, developing blood vessels and undifferentiated cells. The seminiferous tubules appear as solid cords of primitive Sertoli cells and spermatogonia. $\times 170$.

Fig. 2. Electron micrograph of an interstitial cell from a control chick. The cytoplasm contains numerous lipid dropiets partly extracted during tissue preparation. They are frequently associated with mitochondria and membranes of the smooth endoplasmic reticulum. The mitochondria are polymorphic with tubular cristae, a dense matrix and small granular inclusions. The agranular endoplasmic reticulum is sparse and seen as vacuolar structures or as short elongated cisternae. $\times 20,000$. 
PLATE 2

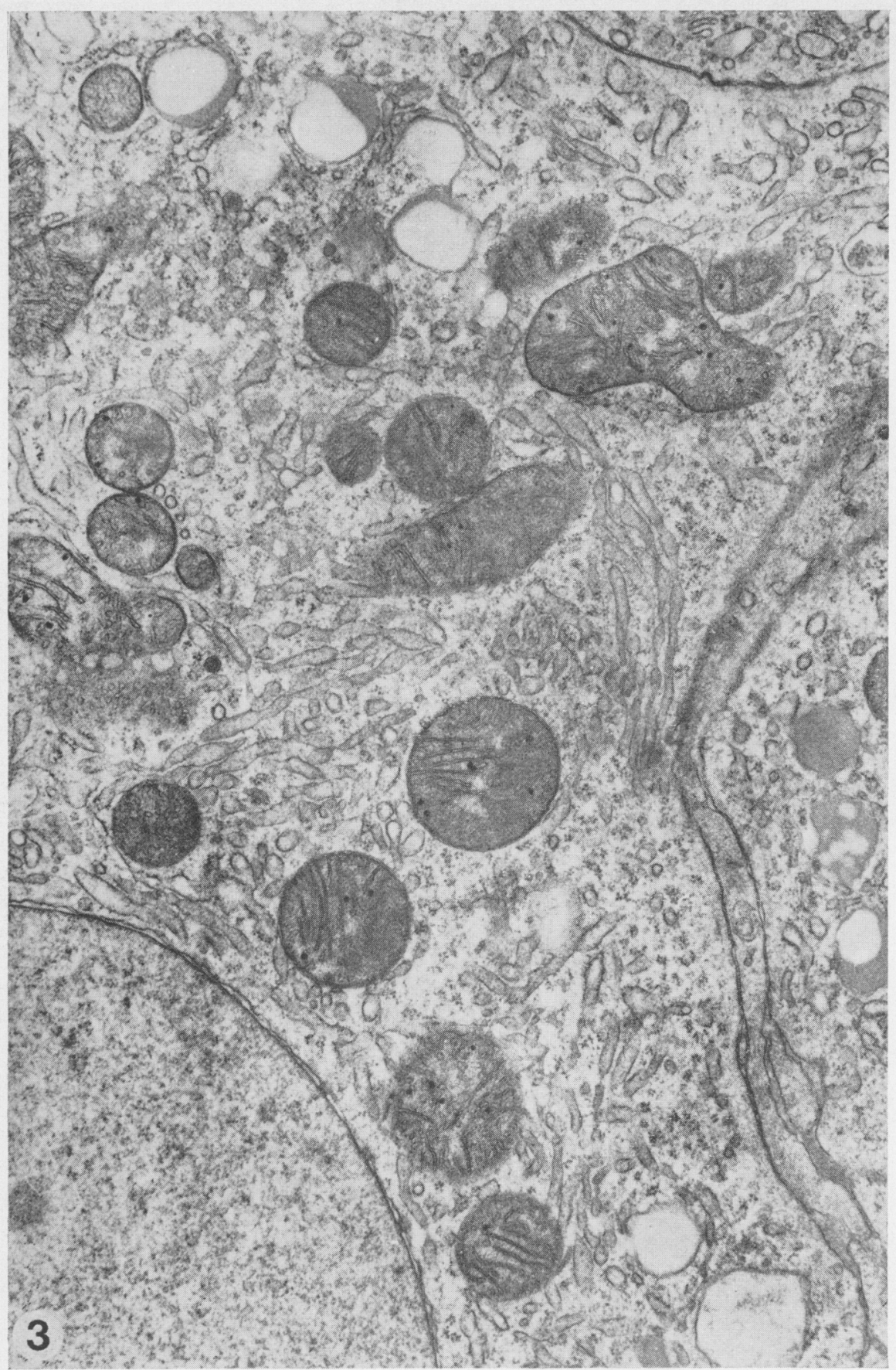

Fig. 3. Electron micrograph of an interstitial cell of a 7-day-old chich lreated with HCG 24 hr before. The cytoplasm exhibits a marked depletion of the lipid inclusions and a considerabie development of membranes of the agranular endoplasmic reticulum. These appear as long tubular membranes of irregular calibre filling all the available space in the cytoplasm. $\times 20,000$. 
terol esters in control testis $(96 \%)$ and this was the only fraction grossly affected by gonadotrophic treatment. This observation supports our previous contention that esterified cholesterol content increased or diminished when Leydig cell function was inhibited or stimulated, respectively. Leydig cells, like other steroid-producing cells, store esterified cholesterol in cytoplasmic lipid inclusions. In a now classic study, Claesson (1954) demonstrated that isolated lipid droplets of the rat ovary contain about $95 \%$ of the intracellular esterified cholesterol. In a comparable study performed with adrenal gland, Moses et al. (1969) found that $75 \%$ of the esterified cholesterol is concentrated in the lipid droplets. In the adrenal gland (Long, 1947; Goodman, 1965) and the ovary (Claesson, 1954; Armstrong, 1968), stimulation of steroidogenesis with the proper trophic hormones was always accompanied by depletion of cholesterol esters. The immediate precursor of steroids is free cholesterol (Dailey et al., 1962; Goodman, 1965; Raggatt \& Whitehouse, 1966; Flint \& Armstrong, 1971), and esterified cholesterol must therefore be hydrolysed as a preliminary step in steroid conversion (Moyle et al., 1970).

The agranular endoplasmic reticulum contains the majority of the enzymes responsible for the biosynthesis of cholesterol (Bucher \& McGarrahan, 1956; Jones \& Armstrong, 1965). In the adult mouse testis, these membranes also constitute the major compartment of free cholesterol (Aoki \& Massa, 1975). The bulk of free cholesterol was also associated with the microsomal fraction in the 7-day-old chick testis and followed closely the increases of testicular weight during the first 18 days after hatching, even though this increased about 4-fold and the concentration of esterified cholesterol decreased about $65 \%$ in the same period. A similar pattern was found in chicks treated with HCG.

The amount of cholesterol mobilized from lipid droplets far exceeds the amount theoretically estimated as substrate for steroidogenesis and it is highly probable that redundant molecules might be used in the assembly of new agranular endoplasmic reticulum (Aoki \& Massa, 1975). This association of free cholesterol with the reticular membranes has been shown by means of the digitonin technique for histochemical localization of free cholesterol (Massa, 1972). The use of radioactive cholesterol in studies of testicular compartmentation (Hall, 1963; Ichihara, 1969) has been disappointing, since the hot cholesterol is rapidly metabolized into androgens and the specific activities in the other cholesterol compartments are greatly distorted by the large pools of endogenous cold cholesterol.

In the adult mouse testis there may be a very slow turnover of free cholesterol or an equilibrium between synthesis and breakdown of the agranular endoplasmic reticulum membranes (Aoki \& Massa, 1972, 1975) to explain the stability of the free cholesterol content. By contrast, in the immature chick testis HCG stimulation causes a striking proliferation of agranular endoplasmic reticulum and since this microsomal compartment is a carrier of the enzyme systems responsible for steroid biosynthesis, its development may be an expression of the differentiation of the androgenic capacity of the interstitial cells.

\section{References}

Aokı, A. (1968) Hormone-induced differentiation of agranular endoplasmic reticulum in the interstitial cells of the mouse testis. Protoplasma 66, 263-267.

Aoki, A. (1970) Hormonal control of Leydig cell differentiation. Protoplasma 71, 209-225.

Aoki, A. \& MASSA, E.M. (1972) Early responses of testicular interstitial cells to stimulation by interstitial-cell-stimulating hormone. Am. J. Anat. 134, 239-261.

AOKı, A. \& MASSA, E.M. (1975) Subcellular compartmentation of free and esterified cholesterol in the interstitial cells of the mouse testis. Cell Tissue Res. 165, 49-62.

ARMSTRONG, D.T. (1968) Gonadotrophins, ovarian metabolism and steroid biosynthesis. Recent Prog. Horm. Res. 24, 255-308.
Black, V.H. \& Christensen, A.K. (1969) Differentiation of interstitial cells and Sertoli cells in fetal guinea pig testes. Am.J. Anat. 124, 211-219.

Bucher, N.L.R. \& McGarrahan, K. (1956) The biosynthesis of cholesterol from acetate-1- $\mathrm{C}^{14}$ by cellular fractions of rat liver. J. biol. Chem. 222, $1-15$.

CONNELL, C.J. (1972) The effect of luteinizing hormone on the ultrastructure of the Leydig cell of the chick. Z. Zellforsch. mikrosk. Anat. 128, 139-151.

Clacsson, L. (1954) The intracellular localization of the esterified cholesterol in the living interstitial gland cell of the rabbit ovary. Acta physiol. scand. 31, Suppl. 113, 53-78.

Creech, B.G. \& Sewell, B.W. (1962) A rapid microprocedure for determination of free and esterified 
cholesterol in blood serum using silicic acid separation. Analyt. Biochem. 3, 119-123.

Dailey, R.E., Swell, L. \& Treadwell, C.R. (1962) Utilization of free and esterified cholesterol-4-C $\mathrm{C}^{\mathbf{1 4}}$ for corticoid biosynthesis by hog adrenal homogenates. Proc. Soc. exp. Biol. Med. 110, 571-574.

Flint, P.F. \& ARmstrong, D.T. (1971) The compartmentation of non-esterified and esterified cholesterol in the superovulated rat ovary. Biochem. J. 123, 143-152.

Folch, J., Lees, M. \& Sloane Stanley, G.H. (1957) A simple method for the isolation and purification of total lipids from animal tissues. J. biol. Chem. 226, 497-509.

Goodman, D.S. (1965) Cholesterol ester metabolism. Physiol. Rev. 45, 747-839.

GreEP, R.O. (1961) Physiology of the anterior hypophysis in relation to reproduction. In Sex and Internal Secretion, Vol. I, pp. 240-301. Ed. W. C. Young, Williams and Wilkins Co., Baltimore.

Hall, P.F. (1963) The effect of interstitial-cell-stimulating hormone on the biosynthesis of testicular cholesterol from acetate-1-C $\mathrm{C}^{14}$. Biochemistry, N.Y. 2, 1232-1237.

Horning, M.G., Williams, E.A. \& Horning, E.C. (1960) Separation of tissue cholesterol esters and triglycerides by silicic acid chromatography. $J$. Lipid Res. 1, 482-485.

ICHIHARA, I. (1969) Cholesterol changes in developing testicular interstitial cells of the mouse: histochemical and biochemical study. Anat. Rec. 163, 595-602.

Jones, A.L. \& ARMSTrong, D.T. (1965) Increased cholesterol biosynthesis following phenobarbital induced hypertrophy by agranular endoplasmic reticulum in liver. Proc. Soc. exp. Biol. Med. 119, 1136-1139.
KARNovsky, M.J. (1965) A formaldehyde-glutaraldehyde fixative of high osmolality for use in electron microscopy. J. Cell Biol. 27, 137A.

LONG, C.N.H. (1947) The relation of cholesterol and ascorbic acid to the secretion of the adrenal cortex. Recent Prog. Horm. Res. 1, 99-122.

MASSA, E.M. (1972) Gonadotrophic control of testicular cholesterol compartments and its correlation with the ultrastructure of Leydig cells. Ph.D. dissertation, Facultad de Ciencias Químicas, Universidad Nacional de Córdoba.

MASSA, E.M. \& AOKI, A. (1971) Simple method for purification of glutaraldehyde. Acta physiol. latinoam. 21, 161-163.

Mollenhayer, H.H. (1964) Plastic embedding mixtures for use in electron microscopy. Stain Technol. 39, 111-114.

Moses, H.L., David, W.W., Rosenthal, A.S. \& GARREN, L.D. (1969) Adrenal cholesterol: localization by electron-microscope autoradiography. Science, N.Y. 163, 1203-1205.

Moyle, W., Jungas, R. \& Greep, R. (1970) Apparent need for cholesteryl palmitate hydrolysis before cholesterol sidechain cleavage in intact testicular tumor mitochondria. Fedn Proc. Fedn Am. Socs exp. Biol. 29, 247A.

Raggatt, P.R. \& Whitehouse, M.W. (1966) Substrate and inhibitor specificity of the cholesterol oxidase in bovine adrenal cortex. Biochem. J. 101, 819830.

Venable, J.H. \& Coggeshall, R. (1965) A simplified lead citrate stain for use in electron microscopy. J. Cell Biol. 25, 407-408.

ZlatkIS, A. \& ZAK, B. (1969) Study of a new cholesterol reagent. Analyt. Biochem. 29, 143-148.

Received 29 January 1976 